\title{
Direct Synthesis of Hydrogen Peroxide in a Trickle Bed Reactor: Comparison of Pd-Based Catalysts
}

\author{
Pierdomenico Biasi, ${ }^{*}{ }^{\dagger}$, Paolo Canu, ${ }^{\ddagger}$ Federica Menegazzo, ${ }^{\S}$ Francesco Pinna, ${ }^{\S}$ and Tapio O. Salmi ${ }^{\dagger}$ \\ ${ }^{\dagger}$ Process Chemistry Centre (PCC), Laboratory of Industrial Chemistry and Reaction Engineering, Åbo Akademi, Biskopsgatan 8, \\ 20500 Turku/Åbo, Finland \\ ${ }^{\ddagger}$ Department of Industrial Engineering, University of Padova, via Marzolo 9, 35131, Padova, Italy \\ ${ }^{\S}$ Department of Molecular Science and Nanosystems, Cà Foscari University and “Consorzio INSTM”, 30123, Venezia, Italy
}

\begin{abstract}
Palladium catalysts based on different supports, silica $\left(\mathrm{SiO}_{2}\right)$, zirconia $(\mathrm{Z})$, sulfated ceria (CeS), and sulfated zirconia (ZS), previously tested in a semibatch reactor, were chosen to demonstrate how the direct synthesis process can be improved by continuous operation in a three-phase fixed bed. The gas and liquid flow rates were systematically varied to find suitable combinations for a maximum hydrogen peroxide production rate and selectivity. Different catalysts gave the same results in terms of selectivity and production rate with different operating conditions. A selectivity of $60 \%$ and $70 \%$ was found with two different catalysts (namely, Pd-ZS and Pd-CeS). Very interestingly those selectivities were found with different gas and liquid flow rates (i.e., $70 \%$ of selectivity for Pd-ZS with liquid $1 \mathrm{~mL} / \mathrm{min}$ and gas $2.7 \mathrm{~mL} / \mathrm{min}$, liquid $0.5 \mathrm{~mL} / \mathrm{min} \mathrm{MeOH}$ and gas $4 \mathrm{~mL} /$ min, and finally liquid $2 \mathrm{~mL} / \mathrm{min} \mathrm{MeOH}$ and gas $1 \mathrm{~mL} / \mathrm{min} 65 \%$ of selectivity for Pd-CeS with liquid $1 \mathrm{~mL} / \mathrm{min}$ and gas $4 \mathrm{~mL} /$ min). Moreover, the same maximum production rate of $\mathrm{H}_{2} \mathrm{O}_{2}$ around $3 \mu \mathrm{mol} / \mathrm{min}$ for $\mathrm{Pd}-\mathrm{CeS}, \mathrm{Pd}-\mathrm{ZS}$, and $\mathrm{Pd}-\mathrm{Z}$ was achieved with different liquid and gas flow rates. Continuous operation and reactor technology play important roles in this green synthesis: optimization of gas and liquid flow rates and contact time between the liquid and the solid (catalysts) phase lead to a dramatic selectivity improvement in a continuous reactor, raising the value obtained in the semibatch reactor from $30 \%$ to $70 \%$.
\end{abstract}

\section{INTRODUCTION}

Hydrogen peroxide has always been regarded as a very interesting and environmentally friendly oxidant with applications confined mainly to bulk sectors of industry, such as the paper and textile industries as well as wastewater treatment.

The direct formation of hydrogen peroxide is in principle the simplest method to obtain hydrogen peroxide, but the reaction scheme (Scheme 1) is more complex because of some

Scheme 1. Reactions Involved in the Direct Synthesis of $\mathrm{H}_{2} \mathrm{O}_{2}$

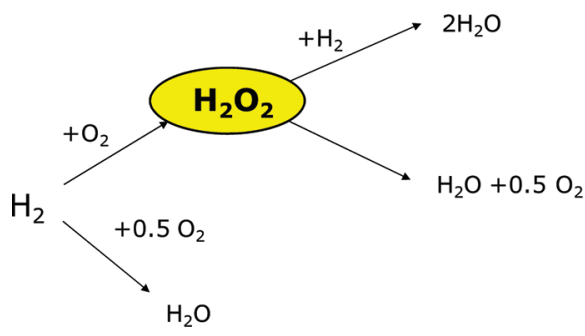

thermodynamically favored side reactions. Each of these reactions may be favored by the catalyst used, the additives in the reaction medium, and the operating conditions. ${ }^{1-6}$ As no extraction of $\mathrm{H}_{2} \mathrm{O}_{2}$ is required and the purification steps are simplified, the capital investment and operating costs are expected to be much lower than those for the classical auto oxidation (AO) process. $^{7-9}$ This alternative is of significant relevance for the chemical industry, especially for an in situ production and integration with other processes, such as the hydrogen peroxide to propylene oxide (i.e., HPPO) process. ${ }^{10}$
The direct synthesis of $\mathrm{H}_{2} \mathrm{O}_{2}$ on site allows the costs and hazards associated with the transport and handling of concentrated hydrogen peroxide solutions to be considerably reduced or eliminated. ${ }^{7,8,11}$ However, there are still productivity and safety issues to be addressed and improved to render this process industrially applicable. ${ }^{7,11}$ The direct process has attracted a renewed interest after 1980 because of the increased demand for $\mathrm{H}_{2} \mathrm{O}_{2}$ due to new environmental perspectives. ${ }^{7,8}$ The direct hydrogen oxidation process has been extensively investigated, leading to a large number of publications in the past few years. ${ }^{1-5,12-18}$ Several patents have been issued since the $1990 \mathrm{~s},{ }^{19-22}$ but no real industrial application has been accomplished to date for the production of bulk $\mathrm{H}_{2} \mathrm{O}_{2}$, and the direct synthesis process has not been commercialized yet. If the process is developed and commercialized successfully in the future, it would be a major breakthrough in the oxidation technology.

The two major issues in the direct synthesis of hydrogen peroxide are related to the process safety and the product selectivity. ${ }^{1,2,7,8,11,15}$ Hydrogen-oxygen mixtures are explosive for a wide range of concentrations, ${ }^{8,11}$ therefore the ratio of hydrogen to oxygen needs to be kept outside the explosive region, alternatively an inert gas, such as nitrogen or carbon dioxide, must be added to the reaction mixture, which

Special Issue: CAMURE 8 and ISMR 7

Received: September 16, 2011

Revised: February 28, 2012

Accepted: March 1, 2012

Published: April 17, 2012 
obviously reduces productivity. ${ }^{1,2,23}$ The other major problem resides in obtaining a good selectivity for hydrogen peroxide, limiting side reactions, because normally the same catalyst that promotes the $\mathrm{H}_{2} \mathrm{O}_{2}$ synthesis also induces its decomposition to yield water. An appropriate solvent is required to carry out the reaction, leading to a three-phase system (solid-catalyst, liquidsolvent, gas- $\mathrm{H}_{2}$ and $\mathrm{O}_{2}$ ), which is difficult to control and optimize. These drawbacks, however, appear to be controllable, and a lot of attention from industry and academia has been directed to the direct synthesis of hydrogen peroxide. ${ }^{1,2,6-8,17,23-25}$

Four different catalysts already tested for hydrogen peroxide direct synthesis in a semibatch reactor ${ }^{5,26}$ were compared in a trickle bed reactor (TBR). The continuous reactor is very important to realize the hydrogen peroxide direct synthesis at industrial scale. Moreover, trickle bed is a well-known reactor that is used in industrial processes. Operating conditions can be varied easier and faster compared to a batch or semibatch reactor. These reasons were taken into account in our final decision on the reactor type. Experiments were designed to demonstrate that different palladium based catalysts behave similarly with different operating conditions. The catalysts chosen for the experimental investigation were $\mathrm{Pd}-\mathrm{SiO}_{2}, \mathrm{Pd}$ CeS (sulfated Ceria), Pd-Z (Zirconia), and Pd-ZS (Sulfated Zirconia). In this study we illustrate how a TBR allows the adjusment of the gas and liquid residence times to achieve enhancements of selectivity, up to $30 \%$, for the catalysts already tested. $^{4,5,26}$ The present work shows how the maximum $\mathrm{H}_{2} \mathrm{O}_{2}$ production rate $(3 \mu \mathrm{mol} / \mathrm{min})$ was achieved with $\mathrm{Pd}-\mathrm{CeS}, \mathrm{Pd}-$ $\mathrm{ZS}$, and $\mathrm{Pd}-\mathrm{Z}$, at the same temperature and pressure, but with different combinations of gas and liquid flow rates. Moreover, with two different catalysts (Pd-CeS and Pd-ZS) the same selectivity (around 70\%) can be obtained with different gas and liquid flow rates. The results demonstrate that in the direct synthesis the direction of the work should be done coupling together reactor and catalyst design.

\section{EXPERIMENTAL SECTION}

Materials. Methanol for HPLC was used as the reaction medium (J.T. Baker 99,99\%), Potassium Iodide (SigmaAldrich), Hydranal-Composite 2 (Fluka), Dry Methanol for KFT (Fluka), Acetic Acid (Sigma-Aldrich), Sodium Thiosulfate penta-hydrate 99,5\% (Sigma-Aldrich), Starch (Sigma-Aldrich), Potassium Dichromate (Riedel de $\mathrm{Haën}$ ), $\mathrm{H}_{2} \mathrm{O}_{2} 30 \%$ w/w (Merck).

Catalyst Preparation. $\mathrm{Pd}-\mathrm{SiO}_{2}$ Catalyst. $\mathrm{SiO}_{2}$ (Akzo) was used as received for samples syntyhesis. It was impregnated by "dry" impregnation with an aqueous solution of $\mathrm{H}_{2} \mathrm{PdCl}_{4}$ to give a nominal $2.5 \% \mathrm{wt}$. Metal loaded catalyst. The sample prepared in this way was dried overnight at $110{ }^{\circ} \mathrm{C}$ and finally calcined at $500{ }^{\circ} \mathrm{C}$ in flowing air for $3 \mathrm{~h}$. The detailed procedure is reported elsewhere. $^{26}$

$P d-Z$ Catalyst. A zirconia support was prepared by precipitation from $\mathrm{ZrOCl}_{2}$ at constant $\mathrm{pH}(\mathrm{pH} 10)$, aged under reflux conditions, washed several times to remove excess of chloride $\left(\mathrm{AgNO}_{3}\right.$ test $)$ and dried overnight at $110{ }^{\circ} \mathrm{C}$. The solution was continuously mixed and boiled for $6 \mathrm{~h}$ at $100{ }^{\circ} \mathrm{C}$, the precipitate was washed twice in boiling deionized water and dried overnight at $110{ }^{\circ} \mathrm{C}$. The support was impregnated by incipient wetness with $\mathrm{H}_{2} \mathrm{PdCl}_{4}$ aqueous solutions to give a nominal $2.5 \mathrm{wt} \%$ metal loaded catalyst and finally calcined at $500{ }^{\circ} \mathrm{C}$ in flowing air for $3 \mathrm{~h}^{4,5}$
Pd-CeS Catalyst. A ceria support substrate was synthesized by precipitation with urea from $\left(\mathrm{NH}_{4}\right)_{2} \mathrm{Ce}\left(\mathrm{NO}_{3}\right)_{6}$ aqueous solution. The solution was continuously mixed for $6 \mathrm{~h}$ at 100 ${ }^{\circ} \mathrm{C}$, the precipitate was washed twice in boiling deionized water and dried in oven at $110{ }^{\circ} \mathrm{C}$ overnight. Ceria material was impregnated by an incipient wetness method with a proper amount of $\left(\mathrm{NH}_{4}\right)_{2} \mathrm{SO}_{4}$ to yield an 8 wt \% anion loading. Impregnated supports were calcined in flowing air $(50 \mathrm{~mL} /$ $\min )$ at $650{ }^{\circ} \mathrm{C}$ for $3 \mathrm{~h}$. Afterward, the calcined supports were impregnated via incipient wetness with $\mathrm{H}_{2} \mathrm{PdCl}_{4}$ aqueous solution to give a nominal 2.5 wt \% Pd-loaded catalyst, and finally calcined again at $500{ }^{\circ} \mathrm{C}$ in flowing air for $3 \mathrm{~h} .{ }^{5}$

$P d$-ZS Catalyst. The zirconia support was prepared as described above. The Zirconia was then impregnated by the incipient wetness method with $\left(\mathrm{NH}_{4}\right)_{2} \mathrm{SO}_{4}$ in amounts necessary to yield an $8 \mathrm{wt} \%$ anion loading. Impregnated supports were then calcined in flowing air $(50 \mathrm{~mL} / \mathrm{min})$ at 650 ${ }^{\circ} \mathrm{C}$ for $3 \mathrm{~h}$. Calcined support was impregnated as described above in the $\mathrm{Pd}-\mathrm{Z}$ section. Detailed preparation is reported by Melada et al. ${ }^{4}$ and Menegazzo et al. ${ }^{5}$

Supports. All the supports (i.e., $\mathrm{SiO}_{2}, \mathrm{Z}, \mathrm{CeS}$, and $\mathrm{ZS}$ ) including the quartz sand were tested with a solution of $\mathrm{H}_{2} \mathrm{O}_{2}$ $0.1 \%$ wt. in methanol; the result is that in $24 \mathrm{~h}$ there is no decomposition of $\mathrm{H}_{2} \mathrm{O}_{2}$ over all the materials used. Only when the metal is deposited on the support hydrogen peroxide decomposition can be detected.

Catalyst Treatment. All the catalysts were crushed and sieved $(0.5-1 \mathrm{~mm})$. Pure $\mathrm{SiO}_{2}$ was crushed and sieved (0.5-1 $\mathrm{mm})$. Each portion of catalyst $(0.16 \mathrm{~g})$ was mixed with $0.2 \mathrm{~g}$ of $\mathrm{SiO}_{2}$ and used as catalytic bed in the continuous reactor. The catalyst was then reduced for $1 \mathrm{~h}$ with a $20 \mathrm{~mL} / \mathrm{min}$ flow of pure hydrogen $\left(1 \mathrm{bar}, 25^{\circ} \mathrm{C}\right.$ ).

Reactor Setup for the Experiments. A cocurrent, downflow TBR previously developed and tested ${ }^{1}$ was used. Besides the advantages already mentioned, the TBR allows short liquid residence time, if required for selectivity. It is a steady-state reactor, so chemical analysis has no limitation on the sampled quantity and does not affect the reactor operation.

The experimental reactor setup is described in detail elsewhere. ${ }^{1}$ Briefly, the reactor is made of AISI 316 stainless steel, $30 \mathrm{~cm}$ long, $1.5 \mathrm{~cm}$ internal diameter (I.D.), internally lined with Teflon ( $1.15 \mathrm{~cm}$ final I.D.) to prevent $\mathrm{H}_{2} \mathrm{O}_{2}$ decomposition due to accessible $\mathrm{Fe}^{3+}$ ions. The reactor is temperature controlled through a jacket, allowing temperatures between -20 and $60{ }^{\circ} \mathrm{C}$. Gas $\left(\mathrm{N}_{2}, \mathrm{O}_{2}, \mathrm{CO}_{2} / \mathrm{H}_{2}\right.$ 97.5/2.5\%) is fed independently by mass flow controllers (MFC) that were calibrated on actual mass flow; volumetric flow rates reported in the figures are calculated with mixture densities determined with a Redlich-Kwong-Soave equation of state with BostonMathias modification, through the Aspen Properties code. The pressure inside the reactor is controlled and regulated with a back pressure controller. A rupture disk is installed for safety reasons. A bypass is used to achieve the desired pressure inside the reactor more rapidly. The liquid phase is fed in through a syringe pump with temperature control, connected to a pressure transducer and computer controlled. Gas and liquids mix before the reactor. A regulation valve is used to sample the instantaneous liquid phase. The catalyst bed $(0.6 \mathrm{~cm}$ long $)$ is placed between two quartz wool plugs. Temperature inside the reactor is measured with a $\mathrm{K}$ thermocouple before the catalyst bed.

$\mathrm{H}_{2} \mathrm{O}_{2}$ Synthesis Experiments and Analyses. The experiments of direct synthesis are carried out at 10 bar and 
$-10{ }^{\circ} \mathrm{C}$, in methanol; the liquid flow rates used were $0.5,1$, and $2 \mathrm{~mL} / \mathrm{min}$. Two gas $\mathrm{H}_{2} / \mathrm{O}_{2} / \mathrm{CO}_{2}$ mixtures were used, namely, $2 / 18 / 80 \%$. The total gas flow rates tested were $1,2,2.7,4,6,9$, and $12 \mathrm{~mL} / \mathrm{min}$. The volumetric total flow rates correspond to specific mass flow rates ranging between 0.063 and $0.254(\mathrm{~kg}$ $\left.\mathrm{m}^{-2} \mathrm{~s}^{-1}\right)$ for the liquid and between 0.0021 and $0.0433\left(\mathrm{~kg} \mathrm{~m}^{-2}\right.$ $\mathrm{s}^{-1}$ ) for the gas. All the experiments have been carried out well in the trickling regime, according to typical flow maps. ${ }^{27}$

We chose to operate the reactor at $-10{ }^{\circ} \mathrm{C}$ because (1) the decomposition and hydrogenation of $\mathrm{H}_{2} \mathrm{O}_{2}$ are slower, while synthesis is less affected by temperature, (2) solubility of $\mathrm{CO}_{2}$ in methanol rises, thus increasing hydrogen solubility in the mixture.

New catalyst is introduced in the reactor without pretreatment. In situ reduction with $\mathrm{H}_{2}(20 \mathrm{~mL} / \mathrm{min})$ at room $T$ and $P$ for $1 \mathrm{~h}$ follows. The reduction state $\left(\mathrm{Pd}^{0}\right)$ is expected to remain after the liquid feed is started and pressurization with a mixture $\mathrm{CO}_{2} / \mathrm{H}_{2}(97.5 / 2.5 \% \mathrm{~mol})$ achieved. When $\mathrm{O}_{2}$ is fed inside the reactor the $\mathrm{Pd}$ is in its reduced form, but because of the large excess of oxygen most probably a PdO layer is formed on the surface of the metal nanoclusters because oxygen is the reagent in excess. ${ }^{4}$

However, it is really difficult to say and understand what is happening inside the reactor because of the complexity of the reaction and the different behaviors of the reagents/products (i.e., $\mathrm{H}_{2}=$ reducing agent, $\mathrm{O}_{2}=$ oxidizing agent, $\mathrm{H}_{2} \mathrm{O}_{2}=$ oxidizing agent). The $\mathrm{O}_{2} / \mathrm{H}_{2}$ mixture is solubilized in the methanol that is in contact with the catalyst. The catalyst surface is continuously in contact with reducing and oxidizing agents, and for that reason probably the metal surface is a mixture of $\mathrm{Pd}^{0}$ and $\mathrm{PdO}$. Although water formation (experimentally measured) is considered an indication of $\mathrm{Pd}^{2+}$ in the absence of promoters (e.g., halide ions and acids), their addition causes $\mathrm{Pd}^{2+}$ to be active for $\mathrm{H}_{2} \mathrm{O}_{2}$ production as well. Nevertheless, it is possible that the actual oxidation state may vary because of the presence of both $\mathrm{O}_{2}$ and $\mathrm{H}_{2}$, whose concentration varies along the bed, because of the reaction and different solubility. The $\mathrm{O}_{2} / \mathrm{H}_{2}$ ratio increases along the bed, possibly changing the local Pd oxidation state.

During each single test, the liquid phase is sampled at the reactor exit, and water (volumetric Karl Fischer) and $\mathrm{H}_{2} \mathrm{O}_{2}$ (iodometric titration) concentration measured. The errors on the measurements of $\mathrm{H}_{2} \mathrm{O}_{2}$ were in the interval of $\pm 3 \%$ and for the measurements of water content in the range of $\pm 4 \%$. Water content is also measured prior to each experiment, before feeding $\mathrm{O}_{2}$. The production rate is defined as mol of $\mathrm{H}_{2} \mathrm{O}_{2}$ produced/min, and it is given by the $\mathrm{H}_{2} \mathrm{O}_{2}$ concentration measured in the liquid sampled (almost pure methanol, after flashing) times the methanol flow rate set at its syringe pump, as representative of the liquid flow rate. Given that all the experiments use the same amount of catalyst $(0.16 \mathrm{~g}$, with real Pd loading of $2.12 \%$ in the Pd-ZS catalyst, $2.69 \%$ in the Pd-CeS catalyst, $2.61 \%$ in the $\mathrm{Pd}-\mathrm{Z}$ catalyst and $3.3 \%$ in the $\mathrm{Pd}-\mathrm{SiO}_{2}$ catalyst), specific production rate in units of mol $\mathrm{H}_{2} \mathrm{O}_{2} \mathrm{~g}_{\mathrm{Pd}}{ }^{-1}$ $\mathrm{h}^{-1}$ can be obtained multiplying the reported data in $\mu \mathrm{mol}$ $\mathrm{H}_{2} \mathrm{O}_{2} / \mathrm{min}$ by 0.0177 for the Pd-ZS catalyst, 0.0139 for the Pd$\mathrm{CeS}$ catalyst, 0.0144 for the Pd-Z catalyst, and 0.015 for the Pd$\mathrm{SiO}_{2}$ catalyst. These values where obtained with the following equation: $\left[10^{-6} \times 60 / 1(\mathrm{~min} / \mathrm{h})\right] /[0.16(\mathrm{~g}) \times \mathrm{Pd}(\%)]$ where $10^{-6}$ is the factor to convert $\mu$ mole into mole, $60 / 1$ to convert the result in hours, 0.16 is the grams of catalyst used during the experiments, and $\mathrm{Pd}$ is the percentage of palladium loaded in the catalyst (note that our results are in $\mu \mathrm{mol} / \mathrm{min}$ ). It should be pointed out that catalyst particles prepared from impregnated powders do not take advantage of all the metal, mostly inaccessible in the particle interior, so that the conversion factor can be higher. The selectivity is defined as $100\left[\mathrm{H}_{2} \mathrm{O}_{2}\right] /\left(\left[\mathrm{H}_{2} \mathrm{O}_{2}\right]+\left[\mathrm{H}_{2} \mathrm{O}\right]_{\text {prod }}\right)$; it is equal to the moles of $\mathrm{H}_{2} \mathrm{O}_{2}$ produced, divided by the moles of $\mathrm{H}_{2}$ consumed.

\section{RESULTS AND DISCUSSION}

Catalyst Properties. The palladium was deposited on all the supports by incipient wetness with $\mathrm{H}_{2} \mathrm{PdCl}_{4}$ aqueous solutions to give a nominal $2.5 \mathrm{wt} \%$ metal loaded catalyst. Brunauer-Emmett-Teller (BET) characterization shows a specific surface area (SSA) for the $\mathrm{SiO}_{2}$ (silica) support of 331 $\mathrm{m}^{2} / \mathrm{g}$ and a SSA for the Z (zirconia) support of $61 \mathrm{~m}^{2} / \mathrm{g}$. For the CeS and ZS the SSA was $29 \mathrm{~m}^{2} / \mathrm{g}$ and $129 \mathrm{~m}^{2} / \mathrm{g}$, respectively. The pore diameter and volume for the $\mathrm{SiO}_{2}$ sample were respectively $9.1 \mathrm{~nm}$ and $1.01 \mathrm{~cm}^{3} / \mathrm{g}$, for the $\mathrm{Z}$ were $21.3 \mathrm{~nm}$ and $0.327 \mathrm{~cm}^{3} / \mathrm{g}$, for the $\mathrm{CeS}$ were $19.5 \mathrm{~nm}$ and $0.099 \mathrm{~cm}^{3} / \mathrm{g}$, and finally for the ZS were $11.1 \mathrm{~nm}$ and 0.332 $\mathrm{cm}^{3} / \mathrm{g}$. The nominal value of Pd loaded was 2.5 wt $\%$ for each sample, but atomic absorption spectroscopy (AAS) reports an actual loading of $3.3 \%$ for $\mathrm{SiO}_{2}, 2.61 \%$ on $\mathrm{Z}, 2.69$ wt \% on $\mathrm{CeS}$, and 2.12 wt $\%$ on ZS. The particle size distribution measured by high-resolution transmission electron microscopy (HRTEM) indicate that the average size of the particles observed in the $\mathrm{Pd}-\mathrm{SiO}_{2}$ catalyst was $2 \mathrm{~nm}$, for the $\mathrm{Pd}-\mathrm{Z}$ catalyst was in the range of $1.5 \mathrm{~nm}$, for the Pd-CeS catalyst was $1.3 \mathrm{~nm}$, and for the Pd-ZS catalyst was $6.4 \mathrm{~nm}$. The amount of sulfate in the sulfated ceria (CeS) and in the sulfated zirconia (ZS) was determined by ion chromatography after dissolution of materials and show a loading of $6.9 \mathrm{wt} \%$ in Ce and $4.2 \mathrm{wt}$ $\%$ in $\mathrm{Z}$. A more detailed characterization is reported elsewhere. ${ }^{4,5,26}$ Catalyst properties are summarized in Table 1.

Table 1. Catalyst Properties Summary

\begin{tabular}{llccccc} 
ref & sample & $\begin{array}{c}\text { SSA } \\
\left(\mathrm{m}^{2} / \mathrm{g}\right)\end{array}$ & $\begin{array}{c}\text { pore } \\
\text { diameter } \\
(\mathrm{nm})\end{array}$ & $\begin{array}{c}\text { pore } \\
\text { volume } \\
\left(\mathrm{cm}^{3} / \mathrm{g}\right)\end{array}$ & $\begin{array}{c}\text { Pd } \\
\text { loaded } \\
(\% \mathrm{w} / \mathrm{w})\end{array}$ & $\begin{array}{c}\text { particle size } \\
\text { distribution } \\
(\mathrm{nm})\end{array}$ \\
26 & $\mathrm{Pd}-S i O_{2}$ & 331 & 9.1 & 1.01 & 3.3 & 2 \\
4,5 & $\mathrm{Pd}-\mathrm{Z}$ & 61 & 21.3 & 0.327 & 2.61 & 1.5 \\
5 & $\mathrm{Pd}-\mathrm{CeS}$ & 29 & 19.5 & 0.099 & 2.69 & 1.3 \\
5 & $\mathrm{Pd}-\mathrm{ZS}$ & 129 & 11.1 & 0.332 & 2.12 & 6.4 \\
\hline
\end{tabular}

Pd-SiO ${ }_{2}$ Catalyst. According to literature, palladium on silica is one of the catalysts which can be used for the hydrogen peroxide direct synthesis. ${ }^{16,26,28,29}$ The catalyst bed is a mechanical mixture of $40 \% \mathrm{Pd}-\mathrm{SiO}_{2}$ catalyst and $60 \%$ pure silica (both crushed and sieved separately). The results for this catalyst are displayed in Figures 1 and 2, for the production rate and selectivity, respectively. A comparison between different liquid flow rates and different gas flow was carried out.

The results for the higher liquid flow rates $(1$ and $2 \mathrm{~mL} / \mathrm{min}$, Figure 1) exhibit a similar trend: close to the lowest gas flow rate, a maximum of the hydrogen peroxide productivity is observed. The maximum of production rate $(1 \mu \mathrm{mol} / \mathrm{min})$ was obtained with a liquid flow rate of $1 \mathrm{~mL} / \mathrm{min}$ and a gas flow rate of $2.7 \mathrm{~mL} / \mathrm{min}$. On the contrary, the lowest liquid flow rate $(0.5$ $\mathrm{mL} / \mathrm{min}$ ) shows a gradual increase in the $\mathrm{H}_{2} \mathrm{O}_{2}$ production rate as the gas-phase residence time increases.

Similar considerations can be reported for the selectivity, as demonstrated by Figure 2, where a maximum for the liquid flow rates of 1 and $2 \mathrm{~mL} / \mathrm{min}$ and a monotonic increase for a liquid 


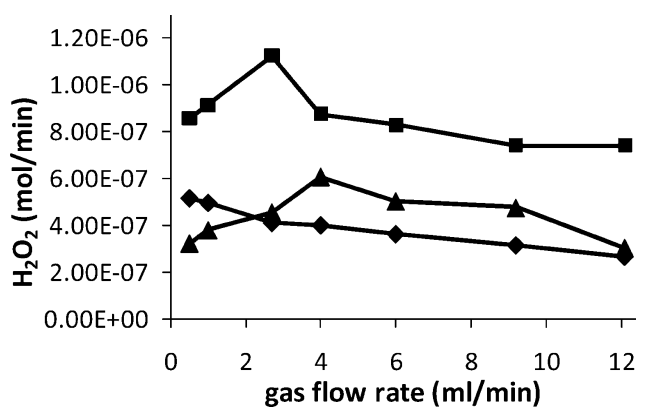

Figure 1. Production rate of $\mathrm{H}_{2} \mathrm{O}_{2}$ for the $\mathrm{Pd}-\mathrm{SiO}_{2}$ catalyst. Combined effect of the gas and methanol flow rates at 10 bar and $-10{ }^{\circ} \mathrm{C}$ : 0.5 $\mathrm{mL} / \mathrm{min}(-), 1 \mathrm{~mL} / \mathrm{min}(-\boldsymbol{-}), 2 \mathrm{~mL} / \mathrm{min}(-\boldsymbol{\Delta}-)$.

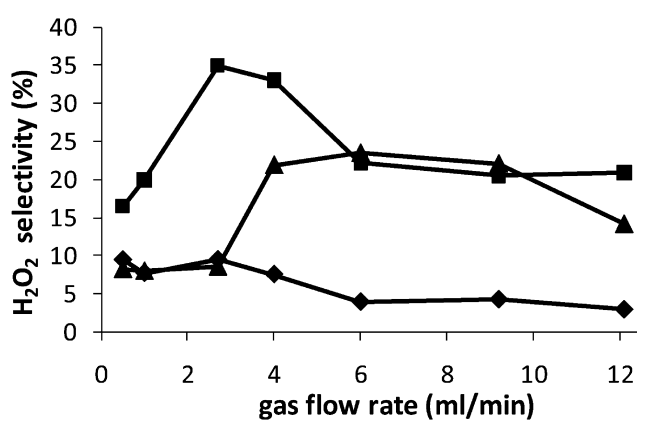

Figure 2. Selectivity of hydrogen peroxide for the $\mathrm{Pd}-\mathrm{SiO}_{2}$ catalyst. Combined effect of the gas and methanol flow rates at $10 \mathrm{bar}$ and -10 ${ }^{\circ} \mathrm{C}: 0.5 \mathrm{~mL} / \mathrm{min}(-), 1 \mathrm{~mL} / \mathrm{min}(-\boldsymbol{-}), 2 \mathrm{~mL} / \mathrm{min}\left(-\boldsymbol{\Delta}_{-}\right)$.

flow rate of $0.5 \mathrm{~mL} / \mathrm{min}$ can be observed. The highest selectivity (around $40 \%$ ) was reached with $1 \mathrm{~mL} / \mathrm{min}$ liquid flow rate and $2.7 \mathrm{~mL} / \mathrm{min}$ gas flow rate. Water is formed during the reaction; the highest amount was detected with a liquid flow rate of $0.5 \mathrm{~mL} / \mathrm{min}$. These experimental facts confirm once more that the reaction pathway largely relies on the contact time between liquid and solid phase. Apparently, an appropriate combination of the gas and liquid flow rate that result in a maximum productivity and selectivity is the same (i.e., $1 \mathrm{~mL} / \mathrm{min}$ liquid and $2.7 \mathrm{~mL} / \mathrm{min}$ gas), which is not always the case with other catalysts, as will be shown in the following.

Pd-Z Catalyst. The second catalyst that was explored for the direct synthesis was a catalyst based on palladium with a zirconia $\left(\mathrm{ZrO}_{2}\right)$ support. This catalyst has been previously tested in a semibatch reactor. ${ }^{4,5}$ The $\mathrm{H}_{2} \mathrm{O}_{2}$ production rate with this catalyst exhibits, for all the liquid flow rates screened, a maximum (Figure 3 ) determined by the gas flow rate used. The highest production rate was achieved $(3.2 \mu \mathrm{mol} / \mathrm{min})$ with a liquid flow rate of $1 \mathrm{~mL} / \mathrm{min}$ of methanol and 2.7 gas flow rate.

The selectivity results are shown in Figure 4, and their interpretation give important information to optimize the catalyst performance by changing the operating conditions in the reactor. This is feasible in the continuous TBR developed previously ${ }^{1}$ and implemented in this work. The maximum value of the selectivity that was reached was $60 \%$, corresponding to a liquid flow rate of $2 \mathrm{~mL} / \mathrm{min}$ and a total gas flow rate of $12 \mathrm{~mL} /$ min. A selectivity of $50 \%$ was achieved with $0.5 \mathrm{~mL} / \mathrm{min}$ liquid flow rate and $6 \mathrm{~mL} / \mathrm{min}$ of gas flow rate. However, the production rate of hydrogen peroxide in the case of $2 \mathrm{~mL} / \mathrm{min}$ $(1 \mu \mathrm{mol} / \mathrm{min})$ is not as high as with a liquid flow rate of 0.5 $\mathrm{mL} / \mathrm{min}(3 \mu \mathrm{mol} / \mathrm{min})$, and at the same time, the water production was very low, as revealed by the selectivity data. As

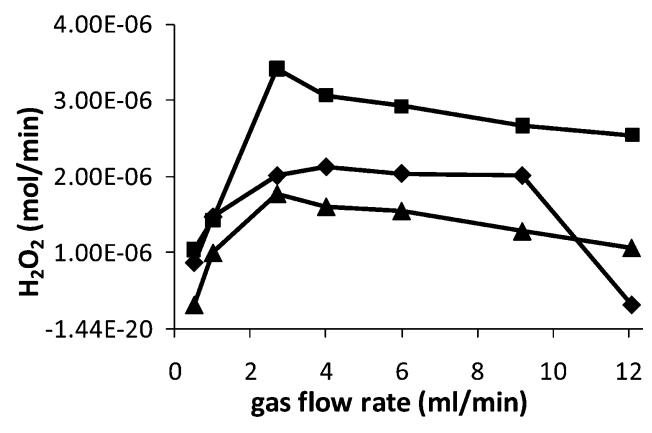

Figure 3. Production rate of $\mathrm{H}_{2} \mathrm{O}_{2}$ for the $\mathrm{Pd}-\mathrm{Z}$ catalyst. Combined effect of the gas and methanol flow rates at 10 bar and $-10{ }^{\circ} \mathrm{C}$ : 0.5 $\mathrm{mL} / \mathrm{min}\left(-\mathbf{-}_{-}\right), 1 \mathrm{~mL} / \mathrm{min}(-\mathbf{-}), 2 \mathrm{~mL} / \mathrm{min}\left(-\boldsymbol{\Delta}_{-}\right)$.

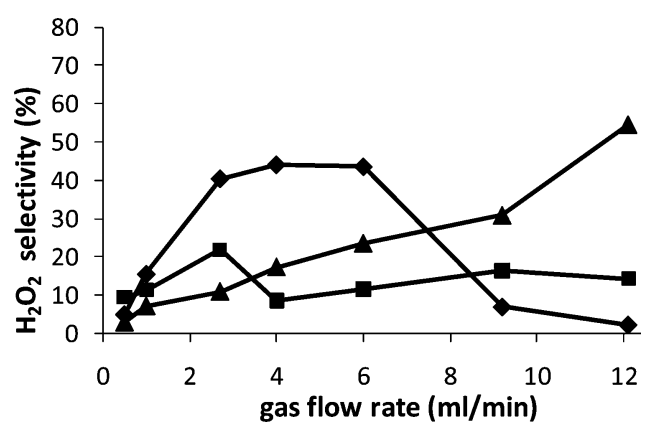

Figure 4. Selectivity of hydrogen peroxide for the $\mathrm{Pd}-\mathrm{Z}$ catalyst. Combined effect of the gas and methanol flow rates at 10 bar and -10 $\left.{ }^{\circ} \mathrm{C}: 0.5 \mathrm{~mL} / \mathrm{min}(-)\right), 1 \mathrm{~mL} / \mathrm{min}(-\boldsymbol{-}-), 2 \mathrm{~mL} / \mathrm{min}\left(-\boldsymbol{\Delta}_{-}\right)$.

a result, the selectivity for hydrogen peroxide became quite high.

As the contact time between liquid and solid phase was reduced (i.e., $1 \mathrm{~mL} / \mathrm{min}$ of methanol), the production of hydrogen peroxide is the highest, but also water formation was increased as clearly indicated by the drop in selectivity. This observation suggests that the decomposition and hydrogenation of $\mathrm{H}_{2} \mathrm{O}_{2}$ occur at a lower flow rate in the catalyst bed with this liquid flow rate. The results for $1 \mathrm{~mL} / \mathrm{min}$ of the liquid flow rate, when compared with the ones relative to 2 $\mathrm{mL} / \mathrm{min}$ methanol, show that the concentration of hydrogen peroxide, at the reactor outlet, is higher; thus, presumably the two reactions of reduction are slower.

Furthermore, looking at Figure 4, it is worth noticing how the selectivity declines rapidly for $0.5 \mathrm{~mL} / \mathrm{min}$ as the liquid flow rate, probably owing to an enhanced water formation as opposed to the hydrogen peroxide production, when the contact time is too short. In the case of this PdZ catalyst, optimal flow rate configuration requires some trade-off between the productivity and the selectivity. In addition, the big effect of both flow rates is somewhat surprising.

Pd-CeS Catalyst. The catalyst consisting of palladium on sulfated ceria was studied extensively. Some results are shown in Figures 5 and 6 to allow for a comparison with the other catalytic systems. Figure 5 is indeed comparable to Figures 1 and 3 , that is, the production of hydrogen peroxide varied nonlinearly with the gas flow rate, often showing a maximum. With this catalyst, the production rate of $\mathrm{H}_{2} \mathrm{O}_{2}$ increased with decreasing liquid flow rates.

The net production of hydrogen peroxide is negatively affected by several side reactions. Hydrogenation and decomposition can be as important as well as the direct 


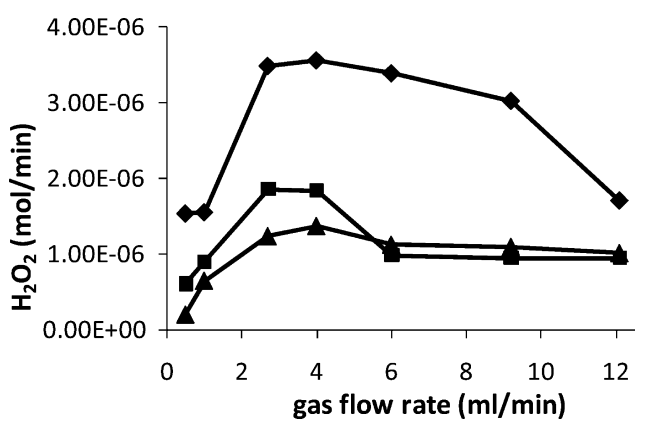

Figure 5. Production rate of $\mathrm{H}_{2} \mathrm{O}_{2}$ for the Pd-CeS catalyst . Combined effect of gas and methanol flow rates at 10 bar and $-10{ }^{\circ} \mathrm{C}: 0.5 \mathrm{~mL} /$ $\min (-\downarrow-), 1 \mathrm{~mL} / \mathrm{min}(-\mathbf{-}), 2 \mathrm{~mL} / \mathrm{min}(-\boldsymbol{\Delta}-)$.

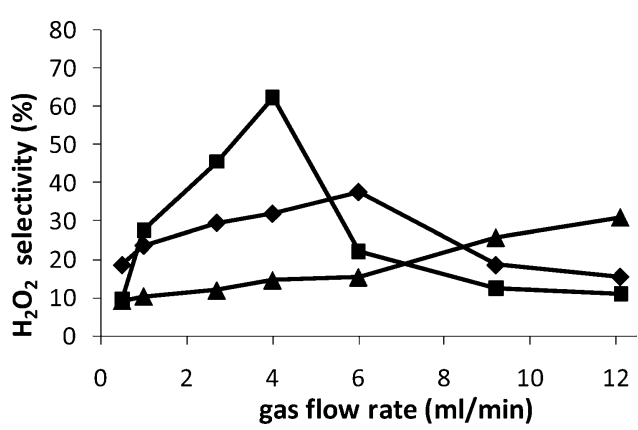

Figure 6. Selectivity of hydrogen peroxide for the Pd-CeS catalyst. Combined effect of gas and methanol flow rates at $10 \mathrm{bar}$ and $-10{ }^{\circ} \mathrm{C}$ : $0.5 \mathrm{~mL} / \mathrm{min}(-), 1 \mathrm{~mL} / \mathrm{min}(-\mathbf{-}), 2 \mathrm{~mL} / \mathrm{min}(-\mathbf{\Delta}-)$.

synthesis path. This fact is clearly visible in Figure 6, in which some selectivity values are presented. Under many circumstances, the selectivity is quite low, clearly indicating the significance of other reactions undesirable for the $\mathrm{H}_{2} \mathrm{O}_{2}$ production.

However, the selectivity can be improved by changing the contact time between the liquid and solid phases. The maximum in the selectivity with this catalyst is $65 \%$ with a liquid flow rate of $1 \mathrm{~mL} / \mathrm{min}$ and a gas flow rate of $4 \mathrm{~mL} / \mathrm{min}$. Therefore, this catalyst can be used efficiently for the synthesis in the TBR. The same catalyst was not so promising when it was tested in a semibatch reactor; in the TBR, the selectivity was enhanced up to $30 \%$ compared with previous results. ${ }^{4,5}$ The contact time between the liquid and the solid phases thus influences the reaction pathway and the product selectivity. Also, the concentration of hydrogen peroxide formed and the duration of the contact with the catalyst is an important factor that can limit or suppress its reduction. In Figure 6 (i.e., selectivity), it can be seen that the contact time obtained from a liquid flow rate of $1 \mathrm{~mL} / \mathrm{min}$ and a gas flow rate of $4 \mathrm{~mL} / \mathrm{min}$ (around $2 \mu \mathrm{mol} / \mathrm{min}$ ) allows the production of a good quantity of hydrogen peroxide with a small quantity of water formed. On the other hand, the selectivity achieved with $2 \mathrm{~mL} / \mathrm{min}$ of liquid flow rate is rather poor, likely because of the low contact time between the liquid and the solid phases. With the liquid flow rate of $2 \mathrm{~mL} / \mathrm{min}$, the water formation is expected to be very low as well as the production of hydrogen peroxide. In turn the selectivity should be higher because of a shorter contact time. The latter is not true, making these results somewhat unexpected, but a reasonable explanation can be inferred. The water formed in this case is to be ascribed once more to the reduction reactions, but also to the direct formation from its elements, a reaction that proceeds in parallel with the $\mathrm{H}_{2} \mathrm{O}_{2}$ formation. This consideration becomes clearer, as the results above are compared to the decomposition studies reported in the previous work. ${ }^{1}$

The direct water formation is the last key step to be eliminated, or at least reduced, to drive the reaction mostly toward the hydrogen peroxide formation. These results confirm the importance of developing both the reactor and the catalyst concepts.

Pd-ZS Catalyst. Sulfated zirconia was a further support considered for a palladium based catalyst. This catalyst has very good properties for the direct synthesis, as previously assessed under semibatch conditions. ${ }^{4,5}$ It shows very good performances also with the TBR. A significant hydrogen peroxide production was achieved with a liquid flow rate of $0.5 \mathrm{~mL} / \mathrm{min}$, as displayed in Figure 7.

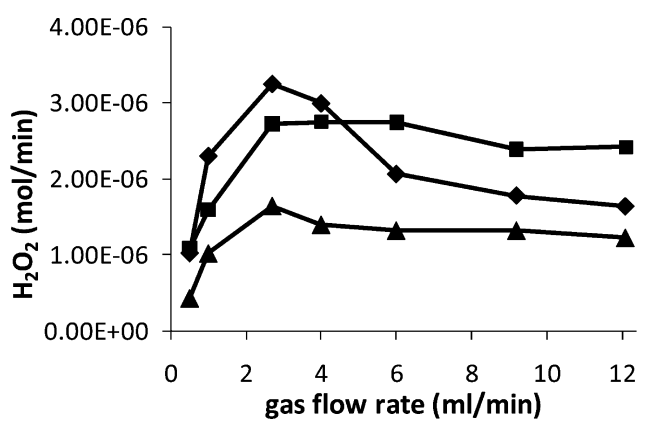

Figure 7. Production rate of $\mathrm{H}_{2} \mathrm{O}_{2}$ for the Pd-ZS catalyst. Combined effect of gas and methanol flow rates at 10 bar and $-10{ }^{\circ} \mathrm{C}: 0.5 \mathrm{~mL} /$ $\min \left(-\mathbf{-}^{-}\right), 1 \mathrm{~mL} / \mathrm{min}(-\mathbf{-}), 2 \mathrm{~mL} / \mathrm{min}\left(-\mathbf{\Delta}_{-}\right)$.

The gas flow rate affects the hydrogen peroxide production as with other catalysts, with a maximum for each of the liquid flow rates examined. The selectivity is shown in Figure 8.

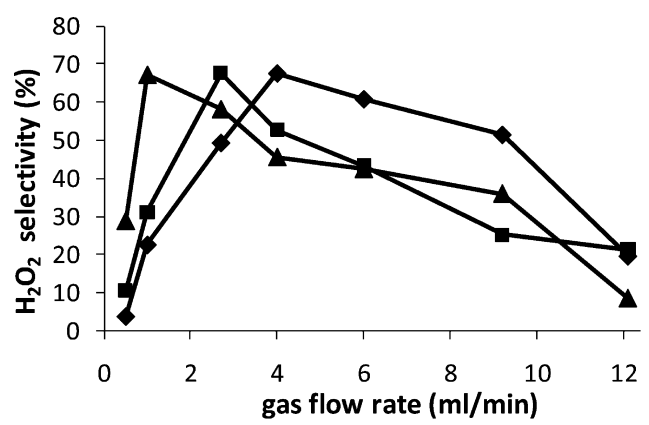

Figure 8. Selectivity of hydrogen peroxide for the Pd-ZS catalyst . Combined effect of gas and methanol flow rates at $10 \mathrm{bar}$ and $-10{ }^{\circ} \mathrm{C}$ : $0.5 \mathrm{~mL} / \mathrm{min}(-), 1 \mathrm{~mL} / \mathrm{min}(-\boldsymbol{-}), 2 \mathrm{~mL} / \mathrm{min}\left(-\boldsymbol{\Delta}_{-}\right)$.

Notably, the maximum selectivity value is about $70 \%$ for all of the three liquid flow rates $(0.5,1$, and $2 \mathrm{~mL} / \mathrm{min})$ combined with different gas flow rates (respectively $4,2.7$, and $1 \mathrm{~mL} /$ $\mathrm{min}$ ). This is a very interesting and industrially promising value, a much higher one than obtained in a semibatch reactor, where the highest selectivity measured was about $50 \% .{ }^{4,5}$ Hence, this particular combination between the catalyst and the reactor shows very interesting results, with a remarkable improvement of the catalyst performance.

As previously reported, the $\mathrm{H}_{2} \mathrm{O}_{2}$ production rate and selectivity often can go to opposite directions, as the liquid and gas flow rates are changed. It is therefore of crucial importance 
to find a good compromise in terms of the operating conditions to have good selectivity while still achieving a satisfactory $\mathrm{H}_{2} \mathrm{O}_{2}$ production rate. With the $\mathrm{Pd}-\mathrm{ZS}$ catalyst considered in this section, two combinations of liquid and gas flow rates turned out to be suitable for achieving good results in the direct synthesis, which correspond to $1 \mathrm{~mL} / \mathrm{min} \mathrm{MeOH}$ with $2.7 \mathrm{~mL} /$ min gas, and $0.5 \mathrm{~mL} / \mathrm{min} \mathrm{MeOH}$ and $4 \mathrm{~mL} / \mathrm{min}$ gas. By selecting these operating conditions, which impact on the contact time between the phases, the values for both the selectivity and the production rate are very promising, showing how this reactor setup, together with an appropriate catalyst, is well suited to enhance the catalyst activity and the hydrogen peroxide yield.

Production Rates. A comparison among the production rates with different catalysts operated at the different liquid flow rate can be described observing Figures 1, 3, 5, and 7 . Comparing the results with a liquid flow rate of $0.5 \mathrm{~mL} / \mathrm{min}$, the highest production rates were achieved with the palladium on the sulfated ceria (Pd-ZS) catalyst. It provides similar results to the Pd-CeS catalyst. The less effective catalyst in this case was the one based on silica.

The earlier results obtained in a semibatch reactor ${ }^{4,5,26}$ agree with the ranking just described. The catalyst based on sulfated zirconia showed a quite good performance, while the production rate with the $\mathrm{Pd}-\mathrm{Z}$ catalyst was not as high, because of the significant water formation compared to the Pd-ZS catalyst (Figures 3 and 7).

In the experiments carried out with a liquid flow rate of $\mathbf{1}$ $\mathrm{mL} / \mathrm{min}$ the best results in terms of hydrogen peroxide production rate were achieved with the $\mathrm{Pd}-\mathrm{Z}$ catalyst, the $\mathrm{Pd}$ ZS still showing good activity in these conditions (Figures 3 and 7). However, the catalyst based on sulfated ceria did not provide a good performance in this case, and the catalyst based on silica remained the worst one (Figures 1 and 3).

Comparing these results (liquid flow rate $1 \mathrm{~mL} / \mathrm{min}$ ) with those presented at $0.5 \mathrm{~mL} / \mathrm{min}$ liquid flow rate, it is worth highlighting how similar the hydrogen peroxide production rates are that can be achieved with different catalysts by varying the operating conditions. The flow rates of $4 \mathrm{~mL} / \mathrm{min}$ gas and $0.5 \mathrm{~mL} / \mathrm{min} \mathrm{MeOH}$ with $\mathrm{Pd}-\mathrm{CeS} ; 2.7 \mathrm{~mL} / \mathrm{min}$ gas and 0.5 $\mathrm{mL} / \mathrm{min} \mathrm{MeOH}$ with $\mathrm{Pd}-\mathrm{ZS} ; 2.7 \mathrm{~mL} / \mathrm{min}$ gas and $1 \mathrm{~mL} / \mathrm{min}$ $\mathrm{MeOH}$ with $\mathrm{Pd}-\mathrm{Z}$ gave comparable results in terms of produced $\mathrm{H}_{2} \mathrm{O}_{2} \mathrm{~mol} / \mathrm{min}$. As a consequence, the reactor setup and the proper choice of the operating conditions can have an impact on the results as significant, if not more, than the catalyst properties. However, as has been reported in the literature, a big effort has been directed toward the catalyst development, $4,5,7,12,15$ while little has been done on the reactor technology ${ }^{1,2,8}$ to understand its role and study how it can affect the reaction pathway, that is, the product selectivity.

The $\mathrm{H}_{2} \mathrm{O}_{2}$ production rate between $\mathrm{Pd}-\mathrm{Z}, \mathrm{Pd}-\mathrm{SiO}_{2}, \mathrm{Pd}-\mathrm{ZS}$, and $\mathrm{Pd}-\mathrm{CeS}$ catalysts and a liquid flow rate of $2 \mathrm{~mL} / \mathrm{min}$, are again reported as stated above in Figures 1,3,5, and 7 . Immediately, it is evident that a higher liquid flow rate diminishes the production of hydrogen peroxide. The profile is still quite similar to that of the experiment with $1 \mathrm{~mL} / \mathrm{min}$ methanol, but the absolute value of the $\mathrm{H}_{2} \mathrm{O}_{2}$ production is lower. This fact is attributed to the shorter contact time between the liquid and solid phases, which reasonably leads to preferential direct water formation, as opposed to hydrogen peroxide.

The results with the $\mathrm{Pd}-\mathrm{Z}$ and $\mathrm{Pd}-\mathrm{ZS}$ catalysts are quite similar (Figures 3 and 7), the former being only slightly better.
The sulfated ceria supported catalyst again shows a reasonable activity, but it is about halved compared with the lower liquid flow rate of $0.5 \mathrm{~mL} / \mathrm{min}$ (Figure 5). The $\mathrm{Pd}-\mathrm{SiO}_{2}$ catalyst was always the worst of the catalysts; its production of $\mathrm{H}_{2} \mathrm{O}_{2}$ was very low compared to that of the other catalysts.

The experiments show how it is possible to optimize the hydrogen peroxide production and how, with different catalysts, to reach the same value of the production rate by varying the operating conditions. The production rate does not give all the information necessary to evaluate the potential industrial effectiveness of the process: it has to be always considered along with selectivity, to find the appropriate operating conditions to optimize the $\mathrm{H}_{2} \mathrm{O}_{2}$ synthesis.

Product Selectivity. The selectivity is the main issue in the direct synthesis of hydrogen peroxide. In Figures 2, 4, 6, 8, the selectivity results for four different catalysts varying liquid flow rate are reported. The data analyses with a liquid flow rate of $0.5 \mathrm{~mL} / \mathrm{min}$ are discussed below.

The Pd-ZS catalyst provided the best selectivity in this case (70\%), showing a good activity for the direct synthesis, as reported previously (Figure 8 ). The best selectivity achieved with this catalyst in a semibatch reactor was approx 50\%.,5 However, a fair comparison between the results obtained with semibatch and TBRs is not easy, as the other conditions differ. The semibatch reactor was operated at $25{ }^{\circ} \mathrm{C}, 1 \mathrm{bar}$, with $\mathrm{H}_{2} \mathrm{SO}_{4}$, continuous flow of gases through the liquid, the liquid simply mixed by the gas flow, glass reactor, $\mathrm{N}_{2}$ as the inert gas. The TBR operated at $-10^{\circ} \mathrm{C}, 10 \mathrm{bar}$, with a continuous flow of gas and liquid, $\mathrm{CO}_{2}$ as the inert gas.

As shown in the figures which report the selectivity (Figures 2,4,6, and 8), with $0.5 \mathrm{~mL} / \mathrm{min}$ of the liquid flow rate, the results for the $\mathrm{Pd}-\mathrm{Z}$ catalyst were quite good also with an higher selectivity measured compared to semibatch conditions. On the other hand, palladium on both sulfated ceria and silica did not show a good selectivity for this liquid flow rate (Figures 2 and 6).

In the experiments with a liquid flow rate of $1 \mathrm{~mL} / \mathrm{min}$, as with $0.5 \mathrm{~mL} / \mathrm{min}$, the best catalyst was again the one based on sulfated zirconia (Figure 8 ). This catalyst gave a very good selectivity (70\%), also with the higher liquid flow of rate of 1 $\mathrm{mL} / \mathrm{min}$. Similarly, the Pd-CeS catalyst showed a good selectivity in this case too (Figure 6); about $63 \%$ of the selectivity is achieved with an enhancement compared to the results in semibatch conditions, where the selectivity was approx $40 \%$. $^{4,5}$ The Pd-CeS catalyst was comparable to the PdZS catalyst (Figure 8).

The importance of the reactor setup can be easily understood from the pictures just presented: different catalysts gave comparable selectivity with different conditions.

The results corresponding to the liquid flow rate of $2 \mathrm{~mL} /$ min show how the $\mathrm{Pd}$ on silica still did not provide a satisfactory performance (Figure 2), and Pd on zirconia in this case showed a poor selectivity as well. It is noticeable how the only catalyst able to provide a good selectivity, despite the very low contact time between the liquid and solid phases, was the Pd-ZS catalyst (Figure 8 ). Pd-CeS showed very poor selectivity (Figure 6).

In general, the profiles relative to the $\mathrm{Pd}-\mathrm{Z}, \mathrm{Pd}-\mathrm{CeS}$, and $\mathrm{Pd}-$ $\mathrm{SiO}_{2}$ catalysts are similar (Figures 2, 4, and 6): with a high enough contact time, the selectivity is acceptable, but when the contact time was small, the selectivity dropped down correspondingly. The selectivity for the Pd-ZS catalyst showed 
a different trend with a high selectivity in the whole range of the gas flow rates examined (Figure 8).

Catalysts and $\mathrm{H}_{2} \mathrm{O}_{2}$ Formation. The catalysts used had different Pd loaded on the support: $\mathrm{Pd}-\mathrm{SiO}_{2}$ had $3.3 \%$ of $\mathrm{Pd}$ on the support, Pd-Z had 2.61\%, Pd-CeS had $2.69 \%$, and Pd-ZS had $2.12 \%$. It was interesting to notice that the best results were obtained (Figures 7 and 8) with the Pd-ZS catalyst that was the catalyst with the lowest percentage of palladium, while the catalyst showing the less promising results (Figures 2 and 3) was the $\mathrm{Pd}-\mathrm{SiO} 2$ with the highest content of palladium. The $\mathrm{Pd}-\mathrm{Z}$ and Pd-CeS catalysts had almost the same amount of metal on the support, $2.69 \%$ and $2.61 \%$, respectively, and surprisingly they had similar results in terms of selectivity and production rate (Figures 4-7). A maximum of $\mathrm{H}_{2} \mathrm{O}_{2}$ peroxide production rate for both catalysts was found around $3.5 \times 10^{-6}$ $\mathrm{mol} / \mathrm{min}$. The maximum selectivity reached (Figures 5 and 7) was slightly different, $55 \%$ for the Pd-Z catalyst and $60 \%$ for the Pd-CeS. The activity of the catalysts from the highest hydrogen peroxide production rate/selectivity to the lowest one was $\mathrm{Pd}$ $\mathrm{ZS}>\mathrm{Pd}-\mathrm{CeS}=\mathrm{Pd}-\mathrm{Z}>\mathrm{Pd}-\mathrm{SiO}_{2}$. The content of metal on the support was as follow Pd-ZS $<\mathrm{Pd}-\mathrm{CeS}=\mathrm{Pd}-\mathrm{Z}<\mathrm{Pd}-\mathrm{SiO}_{2}$. Most probably when the amount of metal was too high the $\mathrm{H}_{2} \mathrm{O}_{2}$ peroxide formed during the reaction had more possibilities to become water thanks to hydrogenation and decomposition reactions. In envisioning developing the catalyst, the metal content of $\mathrm{Pd}$ has to be decreased to verify that a lower percentage of metal on the support will give benefits to the direct synthesis. Another important characteristic of the catalyst is its acidity: the more the support is acid, the more the reaction of the direct synthesis takes advantage of that. We did not find any specific relation between the nanoclusters size of the four different catalysts and their activity for the direct synthesis. We did not find as well any relation between the activity tests and the SSA, the pore volume, and the pore diameter.

We believe that the different porosity of the catalysts did not have any influence on the contact time between the reagents dissolved in the liquid phase and the catalyst. Indeed the amount of the catalysts used for the reaction was really low (i.e., $0.160 \mathrm{~g}$ ). The shape of the catalysts was approximately similar to a sphere with the diameter in the range of $0.5-1 \mathrm{~mm}$. The length of the catalyst bed was approximately $6 \mathrm{~mm}$ and was composed by $40 \%$ of the catalyst and $60 \%$ of pure silica (same shape and diameter of the catalyst). The contact time between the liquid phase and the catalyst is around a few seconds. Thanks to the above conditions the porosity of the catalyst can be neglected in the comments of the results.

\section{CONCLUSIONS}

The most prominent achievement highlighted by the described set of experiments is the dramatic enhancement of the performances of the four catalysts examined $\left(\mathrm{Pd}-\mathrm{SiO}_{2}, \mathrm{Pd}-\mathrm{Z}\right.$, $\mathrm{Pd}-\mathrm{CeS}, \mathrm{Pd}-\mathrm{ZS}$ ) in comparison to previous results obtained in semibatch reactors. This observation confirms the hypothesis that working on the operating conditions can significantly improve the catalyst performance. The crucial role of a continuous reactor was proved, highlighting its importance in optimizing the direct synthesis process of hydrogen peroxide. Obviously, an active catalyst is required to perform the reaction with a high activity and selectivity, but engineering the reactor and reaction system plays an extremely significant role in improving the process and making a further step toward its application on an industrial scale.
The TBR was successfully used to study the behavior of various catalysts under different operating conditions. Studying the process from an engineering viewpoint, and without using promoters or stabilizers in the reaction medium, provides clear information on how varying the operating conditions affect the results. The issue of the secondary unwanted parallel and series reactions was addressed, to limit them as much as possible for higher selectivity results. The work showed that experimental optimization of the TBR is possible to obtain a high selectivity of hydrogen peroxide.

The catalyst support substrate also plays an important role in the direct synthesis of hydrogen peroxide. Palladium supported on sulfated zirconia and sulfated ceria revealed very interesting behaviors in the continuous TBR. The selectivity achieved was up to $70 \%$, with a $40 \%$ enhancement in comparison to the results from a semibatch reactor.

Important information on the direction of catalyst development was obtained. In principle the support should have a high acidity and the particle size should not be too small. Nevertheless combining small nanoparticles with a support with a high acidity can give quite good results. The catalyst with the lowest percentage of metal (i.e., Pd-ZS) works better, while the one with the highest percentage of metal gives the worst results. The development of the catalyst for $\mathrm{H}_{2} \mathrm{O}_{2}$ direct synthesis should be in increasing the acidity of the support and decreasing the amount of palladium on the support.

To improve selectivity and productivity it is necessary to go beyond the catalyst properties, working on the engineering aspects, by optimizing the reactor setup and the operating conditions. Moreover, the hydrodynamics of the TBR will be investigated more deeply to find a relation between the catalysts used and the operating conditions.

\section{AUTHOR INFORMATION}

\section{Corresponding Author}

*E-mail: bpierdom@abo.fi (P.B.).

\section{Notes}

The authors declare no competing financial interest.

\section{ACKNOWLEDGMENTS}

P.B. gratefully acknowledges the Process Chemistry Centre (PCC), Åbo Akademi, and the Johan Gadolin Scholarship for financial support. This work is a part of the Finnish Centres of Excellence Programs (2000-2011) financed by the Academy of Finland.

\section{REFERENCES}

(1) Biasi, P.; Menegazzo, F.; Pinna, F.; Eränen, K.; Canu, P.; Salmi, T. O. Hydrogen Peroxide Direct Synthesis: Selectivity Enhancement in a Trickle Bed Reactor. Ind. Eng. Chem. Res. 2010, 49, 10627-10632.

(2) Biasi, P.; Menegazzo, F.; Pinna, F.; Eränen, K.; Salmi, T. O.; Canu, P. Continuous $\mathrm{H}_{2} \mathrm{O}_{2}$ direct synthesis over PdAu catalysts. Chem. Eng. J. 2011, 176-177, 172-177.

(3) Edwards, J. K.; Thomas, A.; Solsona, B. E.; Landon, P.; Carley, A. F.; Hutchings, G. J. Comparison of supports for the direct synthesis of hydrogen peroxide from $\mathrm{H}_{2}$ and $\mathrm{O}_{2}$ using $\mathrm{Au}-\mathrm{Pd}$ catalysts. Catal. Today 2007, 122, 397-402.

(4) Melada, S.; Rioda, R.; Menegazzo, F.; Pinna, F.; Strukul, G. Direct synthesis of hydrogen peroxide on zirconia-supported catalysts under mild conditions. J. Catal. 2006, 239, 422-430.

(5) Menegazzo, F.; Burti, P.; Signoretto, M.; Manzoli, M.; Vankova, S.; Boccuzzi, F.; Pinna, F.; Strukul, G. Effect of the Addition of Au in Zirconia and Ceria Supported Pd Catalysts for the Direct Synthesis of Hydrogen Peroxide. J. Catal. 2008, 257, 369-381. 
(6) Moreno, T.; Garcia-Serna, J.; Cocero, M. J. Direct synthesis of hydrogen peroxide in methanol and water using $\mathrm{scCO}_{2}$ and $\mathrm{N}_{2}$ as diluents. Green Chem. 2010, 12, 282-289.

(7) Campos-Martin, J. M.; Blanco-Brieva, G.; Fierro, J. L. G. Hydrogen peroxide synthesis: An outlook beyond the anthraquinone process. Angew. Chem., Int. Ed. 2006, 45, 6962-1984.

(8) Centi, G.; Perathoner, S.; Abate, S. Modern Heterogeneous Oxidation Catalysis: Direct synthesis of hydrogen peroxide: recent advances; Wiley-VCH: Weinheim, Germany, 2009; pp 253-287.

(9) Samanta, C. Direct synthesis of hydrogen peroxide from hydrogen and oxygen: An overview of recent developments in the process. Appl. Catal., A 2008, 350, 133-149.

(10) Blanco-Brieva, G.; Capel-Sanchez, M. C.; Pilar, d. F. M.; PadillaPolo, A.; Campos-Martin, J. M.; Fierro, J. L. G. New Two-Step Process for Propene Oxide Production (HPPO) Based on the Direct Synthesis of Hydrogen Peroxide. Ind. Eng. Chem. Res. 2008, 47, 8011-8015.

(11) Piqueras, C. M.; García-Serna, J.; Cocero, M. J. Estimation of lower flammability limits in high-pressure systems. Application to the direct synthesis of hydrogen peroxide using supercritical and nearcritical $\mathrm{CO}_{2}$ and air as diluents. J. Supercrit. Fluids 2010, 56, 33-40.

(12) Burch, R.; Ellis, P. R. An investigation of alternative catalytic approaches for the direct synthesis of hydrogen peroxide from hydrogen and oxygen. Appl. Catal., B 2003, 42, 203-211.

(13) Deguchi, T.; Iwamoto, M. Reaction mechanism of direct $\mathrm{H}_{2} \mathrm{O}_{2}$ synthesis from $\mathrm{H}_{2}$ and $\mathrm{O}_{2}$ over $\mathrm{Pd} / \mathrm{C}$ catalyst in water with $\mathrm{H}^{+}$and $\mathrm{Br}^{-}$ ions. J. Catal. 2011, 280, 239-246.

(14) Deguchi, T.; Iwamoto, M. Kinetics and Simulation Including Mass-Transfer Processes of Direct $\mathrm{H}_{2} \mathrm{O}_{2}$ Synthesis from $\mathrm{H}_{2}$ and $\mathrm{O}_{2}$ over $\mathrm{Pd} / \mathrm{C}$ Catalyst in Water Containing $\mathrm{H}^{+}$and $\mathrm{Br}^{-}$Ions. Ind. Eng. Chem. Res. 2011, 50, 4351-4358.

(15) Edwards, J. K.; Solsona, B.; Ntainjua, N. E.; Carley, A. F.; Herzing, A. A.; Kiely, C. J.; Hutchings, G. J. Switching Off Hydrogen Peroxide Hydrogenation in the Direct Synthesis Process. Science 2009, 323, 1037-1041.

(16) Liu, Q.; Gath, K. K.; Bauer, J. C.; Schaak, R. E.; Lunsford, J. H. The Active Phase in the Direct Synthesis of $\mathrm{H}_{2} \mathrm{O}_{2}$ from $\mathrm{H}_{2}$ and $\mathrm{O}_{2}$ over $\mathrm{Pd} / \mathrm{SiO}_{2}$ Catalyst in a $\mathrm{H}_{2} \mathrm{SO}_{4} /$ Ethanol System. Catal. Lett. 2009, 132, 342-348.

(17) Piccinini, M.; Ntainjua, N. E.; Edwards, J. K.; Carley, A. F.; Moulijn, J. A.; Hutchings, G. J. Effect of the reaction conditions on the performance of Au-Pd/TiO 2 catalyst for the direct synthesis of hydrogen peroxide. Phys. Chem. Chem. Phys. 2010, 12, 2488-2492.

(18) Pritchard, J.; Kesavan, L.; Piccinini, M.; He, Q.; Tiruvalam, R.; Dimitratos, N.; Lopez-Sanchez, J. A.; Carley, A. F.; Edwards, J. K.; Kiely, C. J.; Hutchings, G. J. Direct synthesis of hydrogen peroxide and benzyl alcohol oxidation using Au-Pd catalysts prepared by sol immobilization. Langmuir 2010, 26, 16568-16577.

(19) Miglio, R.; Paparatto, G.; De Alberti, G. Process for the removal of sulfuric acid present in essentially alcoholic solutions of $\mathrm{H}_{2} \mathrm{O}_{2}$ coming from direct synthesis. Patent Application, WO2005063619 A2, 2005.

(20) Paparatto, G.; Rivetti, F.; Andrigo, P.; De Alberti, G. Process for the continuous production of hydrogen peroxide. U.S. Patent 6,649,140, 2003.

(21) Parasher, S.; Rueter, M.; Zhou, B. Nanocatalyst Anchored onto Acid Functionalized Solid Support and Methods of Making and Using. U.S. Patent 7,045,481, 2006.

(22) Zhou, B.; Lee, L. K. Catalyst and Process for Hydrogen Peroxide Production. U.S. Patent 6,168,775, 2001.

(23) Abate, S.; Barbera, K.; Lanzafame, P.; Perathoner, S.; Centi, G. Direct $\mathrm{H}_{2} \mathrm{O}_{2}$ synthesis from $\mathrm{H}_{2}$ and $\mathrm{O}_{2}$ using Pd-SBA-15 and $\mathrm{CO}_{2}$ expanded Solvents. Prepr. - Am. Chem. Soc., Div. Pet. Chem. 2008, 53, 227-229.

(24) Moreno, T.; García-Serna, J.; Cocero, M. J. Decomposition reaction of $\mathrm{H}_{2} \mathrm{O}_{2}$ over $\mathrm{Pd} / \mathrm{C}$ catalyst in an aqueous medium at high pressure: Detailed kinetic study and modelling. J. Supercrit. Fluids 2011, 57, 227-235.

(25) Abate, S.; Centi, G.; Perathoner, S.; Melada, S.; Pinna, F.; Strukul, G. The issue of selectivity in the direct synthesis of $\mathrm{H}_{2} \mathrm{O}_{2}$ from
$\mathrm{H}_{2}$ and $\mathrm{O}_{2}$ : the role of the catalysts in relation to the kinetic of reaction. Top. Catal. 2006, 38, 181-193.

(26) Ghedini, E.; Menegazzo, F.; Signoretto, M.; Manzoli, M.; Pinna, F.; Strukul, G. Mesoporous silica as supports for Pd catalyzed $\mathrm{H}_{2} \mathrm{O}_{2}$ direct synthesis: Effect of the textural properties of the support on the activity and selectivity. J. Catal. 2010, 273, 266-273.

(27) Ramachandran, P. A.; Chaudhari, R. V. Three-Phase Catalytic Reactors; Gordon and Breach: New York, 1983.

(28) Liu, Q.; Lunsford, J. H. Controlling Factors in the Direct Formation of $\mathrm{H}_{2} \mathrm{O}_{2}$ from $\mathrm{H}_{2}$ and $\mathrm{O}_{2}$ over a $\mathrm{Pd} / \mathrm{SiO}_{2}$ Catalyst in Ethanol. Appl. Catal., A 2006, 314, 94-100.

(29) Park, S.; Baeck, S.-H.; Kim, T. J.; Chung, Y.-M.; Oh, S.-H.; Song, I. K. Direct synthesis of hydrogen peroxide from hydrogen and oxygen over palladium catalyst supported on $\mathrm{SO}_{3} \mathrm{H}$-functionalized mesoporous silica. J. Mol. Catal. A: Chem. 2009, 319, 98-107. 